\title{
(2) OPEN ACCESS \\ Informed consent and assent guide for paediatric clinical trials in Europe
}

\author{
Pirkko Lepola (1) , ${ }^{1}$ Maxine Kindred, ${ }^{2}$ Viviana Giannuzzi, ${ }^{3}$ Heidi Glosli, ${ }^{4}$ \\ Martine Dehlinger-Kremer, ${ }_{1}^{5}$ Harris Dalrymple, ${ }_{9}^{5}$ David Neubauer, ${ }^{6}$ Geraldine B Boylan, ${ }^{7}$ \\ Jean Conway, ${ }^{8}$ Jo Dewhurst, ${ }^{5}$ Diane Hoffman ${ }^{9}$
}

${ }^{1}$ University of Helsinki and Helsinki University Hospital, Department of Children and Adolescents, Helsinki, Finland ${ }^{2}$ Portfolio Delivery Operations, Janssen Research \&

Development, High Wycombe, UK

${ }^{3}$ Research Department,

Fondazione per la Ricerca Farmacologica Gianni Benzi onlus, Bari, Italy

${ }^{4}$ Paediatric Clinical Trial Ward, Oslo University Hospital, Oslo, Norway

${ }^{5}$ Center for Pediatric Clinical Developmen, ICON plc, Dublin, Ireland

${ }^{6}$ Department of Child, Adolesecent \& Developmental Neurology, University Medical Centre Ljubljana, Children's Hospital Ljubljana, Ljubljana, Slovenia

${ }^{7}$ Department of Paediatrics and Child Health, Neonatal Brain Research Group, Cork University Maternity Hospital, Cork, Ireland ${ }^{8}$ Department of Paediatrics \& Child Health, University College Cork, Cork, Ireland

${ }^{9}$ Retired from work, Janssen Research and Development LLC, Raritan, New Jersey, USA

\section{Correspondence to}

Mrs Pirkko Lepola, University of Helsinki and Helsinki University Hospital, Department of Children and Adolescents, 00029 Helsinki, Finland; pirkko.lepola@hus.fi

Received 6 July 2021 Accepted 27 October 2021

\section{Check for updates}

(c) Author(s) (or their employer(s)) 2021. Re-use permitted under CC BY-NC. No commercial re-use. See rights and permissions. Published by BMJ.

To cite: Lepola P, Kindred M, Giannuzzi V, et al.

Arch Dis Child Epub ahead of print: [please include Day

Month Year]. doi:10.1136/

archdischild-2021-322798

\section{ABSTRACT}

Objective Clinical trial sponsors spend considerable resources preparing informed consent (IC) and assent documentation for multinational paediatric clinical trial applications in Europe due to the limited and dispersed patient populations, the variation of national legal and ethical requirements, and the lack of detailed guidance. The aim of this study was to design new easy-to-use guide publicly available on European Medicines Agency's, Enpr-EMA website for all stakeholders.

Methods Current EU legal, ethical and regulatory guidance for paediatric clinical trials were collated, analysed and divided into 30 subject elements in two tables. The European Network of Young Person's Advisory Group reviewed the data and provided specific comments. A three-level recommendation using 'traffic light' symbols was designed for four age groups of children, according to relevance and the requirements.

Results A single guide document includes two tables: (1) general information and (2) trial-specific information. In the age group of 6-9 years old, $92 \%$ of the trialspecific subject elements can be or should be included in the IC discussion. Even in the youngest possible age group ( $2-5$ years old children), the number of elements considered was, on average, $52 \%$.

Conclusion The EU Clinical Trial Regulation (2014) does not contain specific requirements exclusively for paediatric clinical trials. This work is the first to extensively collate all the current legal, regulatory and ethical documentation on the IC process, together with input from adolescents. This guide may increase the ethical standards in paediatric clinical trials.

\section{INTRODUCTION}

Children represent $20 \%$ of the European population ( $\sim 90$ million citizens). ${ }^{1}$ In 2020 , on average, $11 \%$ of all clinical trials registered into the European Clinical Trials database (EudraCT) were paediatric clinical trials with investigational medicinal product. ${ }^{2}$ Due to the EU Paediatric Regulation, ${ }^{3}$ all new clinical trials with medicinal products must consider if the inclusion of children (0-18 years of age) from all or some age ranges is relevant, which means the number of paediatric clinical trials will increase. The number of participants per country can be very small.

These multicentre and multinational trials create demanding research environment for academic groups and pharmaceutical industry in Europe, as they spend considerable time and resources

\section{What is already known on this topic?}

Paediatric clinical trial sponsors spend considerable resources preparing informed consent (IC) and assent documents for multinational paediatric Clinical Trial Applications in Europe.

- There are no detailed and easy-to-use public guide for designing of IC and assent forms for paediatric multicentre clinical trials.

- Many national legal and ethical guidance still lack practical common advice for design of IC documents for children and ensuring children's involvement.

\section{What this study adds?}

- This guide provides practical instructions for legal and ethical requirements for IC and assent for children of all age groups.

- This guide includes input from children, providing ideas on how to enhance the involvement of children in the IC process.

- This guide supports sponsors' Clinical Trial Application submissions to Competent Authorities and Ethics Committees, enhancing the high-quality ethical standards of paediatric clinical trials.

preparing documentation for clinical trial application. The submission packages for the competent authorities and ethics committees including informed consent (IC) and assent documents are challenging due to non-harmonised legislation and wide variation between national regulatory requirements. ${ }^{45}$

In Europe, the legal age for giving independent IC for participation in a clinical trial varies between 14 and 18 years. In paediatric trials, the consent process includes the child's own consent, assent or agreement. According to many national laws, a child's own assent is usually not sufficient alone to allow his/her participation, unless supplemented by the consent of the child's legally designated representative(s). ${ }^{46}$

Legal, ethical and regulatory framework for paediatric clinical trials in Europe

After the EU Paediatric Regulation (EC No 1901/2006), ${ }^{3}$ in 2014 the EU Clinical Trials 
Regulation followed ${ }^{7}$ the current EU Clinical Trial Directive. ${ }^{8}$ The clinical trials regulation will facilitate clinical trials in the EU after it will come into application on 31 January 2022. Under this regulation, ethical review will remain under each EU Member State according to their national laws. In May 2018, the new EU General Data Protection Regulation ${ }^{9}$ came into force, impacting clinical trials and consent process, requiring an explanation of the legal basis for the collection and processing personal data on trials. Some countries require even explicit consent for data processing.

The ethical foundation for clinical research is the updated World Medical Association's Declaration of Helsinki (WMA $\mathrm{DoH}),{ }^{10}$ incorporated into the International Conference on Harmonisation (ICH) Good Clinical Practice (GCP) guideline. ${ }^{11}$ Both principles of the WMA DoH and GCP are evident in the EU Clinical Trial Regulation. In 2017, the EU Commission's revised version of the EU ethics guideline for paediatric clinical trials was published. ${ }^{6}$

\section{Children's right to be involved in clinical trial design and IC process}

According to the current legal texts and ethical recommendations, children should be able to take part in the consent process. A child's participation is derived from the general requirements for the right to express their own opinions from the Fundamental rights of the Convention on the Rights of the Child. ${ }^{12} 13$

The increased patient and parent involvement have evolved after the European Young Person's Advisory Groups (eYPAGnet) was established in 2017. ${ }^{14}$ The eYPAGnet is a consortium of Young People's Advisory Groups (YPAGs) across Europe, supporting the development of new national YPAGs. The YPAG provide a platform for children to have a voice, share their opinions and apply their experience to a variety of issues in clinical trials, such as ICs and assents. These groups include young people aged between 8 and 19 years (even up to 21 years) who are patients and/or healthy children having an interest in science, healthcare and children's rights. ${ }^{15}$

Comprehensive trial information must always be presented to the child's legal representative(s) both orally and in writing. ${ }^{6}$ Trial information should be also provided to the child participant, but it should be adapted to the child's language skills and understanding, the child's developmental stage, intellectual capacity, medical condition, previous life/disease experience and other circumstances. Chronological age only partly correlates with maturity. The maturity is evaluated by the investigator. Where appropriate, translation should be arranged. It is very important to identify a child's potential dissent or disagreement to participate, which should always be respected. ${ }^{6}$

\section{Enpr-EMA facilitates the main objective of the paediatric regulation}

In 2013, the European Network of Paediatric Research at the European Medicines Agency (Enpr-EMA) initiated various multistakeholder working groups to find solutions to emerging medical needs related to paediatric clinical trials. ${ }^{16-18}$ The ethics working group has focused on ethical issues in paediatric clinical trials and published first 'Tool Kit' of European informed consent and assent requirements in December $2015^{19}$ and related article later in May $2016 .^{4}$

\section{The aim of the new guide for paediatric ICs and assents}

Some EU-funded projects and learnt societies have developed new practical tools, guidance, design methods and training programmes for supporting paediatric clinical trials. ${ }^{20-25}$ The aim of this new guide was to provide more practical easy-to-use tool for designing the content of IC and assent documents to enhance the high-quality ethical standards of paediatric clinical trials. This guide can be adapted to all types of paediatric clinical trials on a case-by-case basis, and it can also be used to promote the involvement of children in the consent process. This guide was initially published on Enpr-EMA website on January 2021. ${ }^{26}$

\section{METHODS}

The working group collated all current EU legislative, ethical and regulatory legal texts specific to paediatric clinical trials via literature search and used these as the primary data source.

A total of 30 identified main subject elements required for the consent process in legal, ethical or regulatory texts were divided into two tables based on the nature of the requirement. The first table is applicable to all trials (5 general elements) and the second table includes trial-specific topics (25 elements), which can vary between trial design (table 1$)$. All subject elements were considered for four paediatric age groups $(0-2 ; 2-5 ; 6-9 ; 10-18)$ and legal representative(s) as defined in the EU ethics guideline. ${ }^{6}$

A three-level recommendation was established as 'traffic light' symbols. These were used to separate subject elements to be considered, not considered or categorised as optional according to the age group per each subject element (table 2).

The three-level recommendation was reviewed against each subject element $(5+25$ elements $)$ and across all age groups. All elements were sorted with the symbols to separate each subject element according to suitability for each age group and this resulted in recommendations per age group.

All subject elements were listed separately as these are unrelated to each other. The data were then arranged into five vertical main sections (columns) (I-V): (I) age group in years, (II) legal representative(s), (III) elements to consider/information which must be included in the assent/consent document, (IV) questions to be addressed, and (V) notes and example methods/texts to be used. The first heading (I) includes four age group columns. One additional sixth section (column VI) was added to table 4 for the element numbering (tables 3 and 4). Both tables include text partly written in bold, emphasising the most important aspects, or requirement, need to be considered.

After structural design, the eYPAGnet members of three national YPAGs (the UK, Scotland and Spain) were requested to review all 30 subject elements in order to identify important information, any issues or missing information and the preferred format of given information for a practical consent discussion. All comments were collected by monographic sessions led by the group facilitators. All feedback was collated into the report. The report data were incorporated into the guide's section IV, as questions, example methods or texts to be used when designing consent/assent documents, or when recruiting paediatric participants to trials.

The last review for the complete guide was done by the Office of the Paediatric Medicines (Scientific Evidence Generation Department) at the European Medicines Agency. The guide document was finalised according to these comments (figure 1).

\section{RESULTS}

\section{Subject elements adaptable and suitable for various age} groups is very high

After all the subject elements were collated, it clearly illustrated the complexity of IC forms and the consent process in the paediatric population. Many items must be discussed in an adapted 
Table 1 Subject elements of IC and assent guide tables 3 and 4

\begin{tabular}{|c|c|}
\hline $\begin{array}{l}\text { No of subject } \\
\text { element }\end{array}$ & Subject element to consider, information which must be included in the IC/assent document \\
\hline Guide table 3 & General \\
\hline 1.1 & $\begin{array}{l}\text { Language, translations, visual materials, methods for giving information, time used for IC process, unbiased approval, competent personnel for the process and the } \\
\text { documentation }\end{array}$ \\
\hline 1.2 & Concept of the clinical trial methodology \\
\hline 1.3 & Dissent, refusal, disagreement, voluntariness, free decision and respect for autonomy \\
\hline 1.4 & Legal representative(s) roles, sensitive issues for adolescents \\
\hline 1.5 & IC/assent/agreement signatures and re-consenting (long-term studies) \\
\hline Guide table 4 & Trial specific \\
\hline 2.1 & Clinical trial introduction; title, topic, purpose, size (no of participants) \\
\hline 2.2 & Protocol introduction; duration, visits, procedures (trial plan) \\
\hline 2.3 & Participant selection and recruitment process \\
\hline 2.4 & Information about the institution/organisation (ie, hospital) and the personnel involved in the trial \\
\hline 2.5 . & Introduction of the investigational medicinal product(s) and placebo, or device(s) used in trial \\
\hline 2.6 & Introduction of other treatment options and alternatives for trial \\
\hline 2.7 & Possible benefits or expected benefits of the clinical trial for the participant \\
\hline 2.8 & Information about procedures, tests, samples, measurements and possible pain or discomfort included to the trial conduction, how these are prevented and minimised \\
\hline 2.9 & Detailed information about trial time; visits, timing, place, schedules \\
\hline 2.10 & Introduction of possible risks, disadvantages, side effects or other inconveniences of the trial medication or the trial procedures \\
\hline 2.11 & Information about genetic testing if included to the trial \\
\hline 2.12 & Use of ionising radiation if used in trial procedures \\
\hline 2.13 & Biological samples; handling, storage, retention, banking, data use if included to the trial \\
\hline 2.14 & Possible future effect to fetus/sperm \\
\hline 2.15 & $\begin{array}{l}\text { Special conditions; emergency, emancipated minor, pregnancy, breast feeding, unexpected problems, change of the legal representative(s) or other changes during the } \\
\text { trial conduction }\end{array}$ \\
\hline 2.16 & Confidentiality and Data Protection (GDPR) \\
\hline 2.17 & Information about discontinuation and right to withdraw, discontinuation for medical or safety reasons, adverse effect reporting \\
\hline 2.18 & Information about trial costs, medicine costs and expenses and allowed compensation NOTE: incentives or inducements are forbidden by EU law \\
\hline 2.19 & Information about patient insurance and other applicable damage compensations \\
\hline 2.20 & After trial measurements and follow-up period if included \\
\hline 2.21 & Results of the trial \\
\hline 2.22 & Information about the Competent Authorities (ethics, medicine agency) and appropriate expertise needed for trial authorisation \\
\hline 2.23 & Information about clinical trial sponsor and trial funding \\
\hline 2.24 & Contact information for trial personnel \\
\hline 2.25 & Confirmation of understanding—verification with some method \\
\hline
\end{tabular}

IC, informed consent.

manner according to their age and maturity representing all possible therapeutic areas and diseases, from healthy subjects (eg, vaccine trials) to extremely rare disease patient groups.

Listing trial-specific subject elements (25 elements of table 4) relevant to all paediatric clinical trials resulted in all elements $(100 \%)$ being relevant and to be considered when designing and conducting clinical trials in the oldest age group. Further, when looking at children in the age group 6-9 years, 23 out of 25 (92\%) elements can be optionally included or should be included in adapted ways in the consent process. Even in the youngest possible age group, the number of optional or recommended elements is still high; $12-14$ out of 25 (on average 52\%). The

\begin{tabular}{ll}
\hline Table 2 & Three-level recommendation symbols for all age groups \\
\hline Symbol & Description \\
\hline $\begin{array}{l}\text { Does not have to be included in the assent/agreement/informed } \\
\text { consent process for this age group }\end{array}$ \\
$\begin{array}{l}\text { Should be included and discussed during the assent/agreement/ } \\
\text { informed consent process for this age group }\end{array}$ \\
$\begin{array}{l}\text { May be included/optional to include in the assent/agreement/informed } \\
\text { consent process for this age group }\end{array}$
\end{tabular}

inclusion of small children (under 2 years) is discussed only with the legal representative(s) (figure 2).

\section{The specific questions addressed to adolescents in the consent discussion}

The comments received from the eYPAGnet members resulted in a high number of recommended questions (81) to adolescents per each subject element. The total number of questions in both tables ( 3 and 4 ) is 86 , and the number of questions varies between one and six per subject element. The first five questions to the table 3 were generated by the working group.

\section{DISCUSSION}

The practical challenges in the implementation of paediatric multicentre clinical trial

Paediatric clinical trial design and recruitment need specific expertise and experienced, qualified and trained personnel. Similar experience is required from the people reviewing and assessing the trial protocols, patient information, consent and the assent or agreement forms. ${ }^{6}$ 
Table 3 General information for informed consent and assent (agreements)

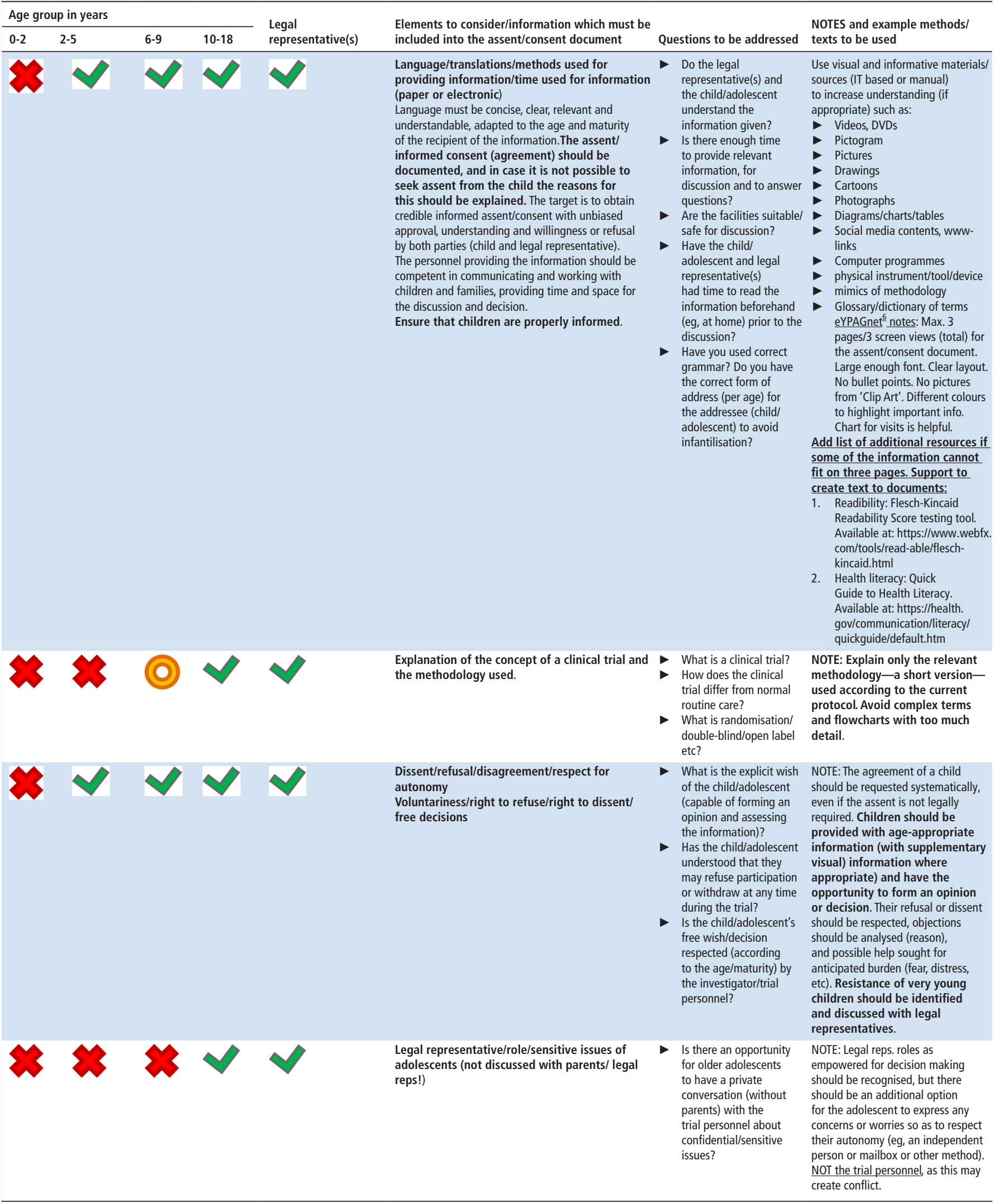


Table 3 Continued

\begin{tabular}{|c|c|c|c|c|c|c|c|}
\hline \multicolumn{4}{|c|}{ Age group in years } & \multirow{2}{*}{$\begin{array}{l}\text { Legal } \\
\text { representative(s) }\end{array}$} & \multirow{2}{*}{$\begin{array}{l}\text { Elements to consider/information which must be } \\
\text { included into the assent/consent document }\end{array}$} & \multirow[b]{2}{*}{ Questions to be addressed } & \multirow{2}{*}{$\begin{array}{l}\text { NOTES and example methods/ } \\
\text { texts to be used }\end{array}$} \\
\hline $0-2$ & $2-5$ & $6-9$ & $10-18$ & & & & \\
\hline & Oth & & & & $\begin{array}{l}\text { Assent/consent signature/certification/re- } \\
\text { consent after legal age (CTR:Article } 32 \text { ); In } \\
\text { long-term studies, check if there is a need to } \\
\text { re-assent the child as the child matures. } \\
\text { Check, if assent (consent) is legally required for } \\
\text { the child (national laws). } \\
\text { The child/adolescent must take part in the } \\
\text { informed consent procedure in a way adapted to } \\
\text { their age and mental maturity. A child/adolescent } \\
\text { capable of forming an opinion and assessing the } \\
\text { information should also provide their assent to } \\
\text { participate in the trial. The assent may additionally be } \\
\text { in written form and must be according to national } \\
\text { requirements. }\end{array}$ & $\begin{array}{l}\text { Who can/must sign/write } \\
\text { name on assent/consent } \\
\text { forms? }\end{array}$ & $\begin{array}{l}\text { For younger children, parents can } \\
\text { explain by using "story telling" } \\
\text { method. }\end{array}$ \\
\hline
\end{tabular}

Bolded texts in columns: The most important aspects, or requirement, need to be addressed per each subject element to consider

*European Medicines Agency, 2021. Reproduced with permission.

Pharmaceutical companies and Contract Research Organisations have their own document templates, resulting in hundreds of different consent and assent documents submitted to European ethics committees, which repeatedly receive incomplete or inappropriate documentation for paediatric clinical trials. The most problematic area is patient information and consent forms, as these are often too complex for children to understand, and too extensive to read and comprehend. The language is often targeted for adults. The child's participation cannot rely on the adult IC, which applies to decisions made by those with the legal and intellectual capacity to make such choices. Children usually lack such capacity, and they need adapted information.

Repeated amendments and committee's re-evaluations prolong ethics approvals and cause delays to the start of clinical trials, causing unnecessary loss of time and money. To avoid such pitfalls, consent and assent documents need to be designed according to high ethical standards. ${ }^{627-31}$

\section{The age groups of children can be used for different purposes depending on scope}

The International Conference of Harmonisation (ICH) E11 Guideline ${ }^{32}$ lists five age groups (preterm newborn infants, term newborn infants; $0-27+$ days, infants and toddlers; 28 days to 23 months, children; $2-11$ years and adolescents; 12 to $16-18$ years dependent on the region). This ICH guideline is scoped for trial design, covering, for example, pharmacological assessment and outcome measures based on physiological development and pathophysiology. Four age groups used in this consent and assent guide document $(0-2 ; 2-5 ; 6-9 ; 10-18$ years $)$ are those described in the EU ethics guideline ${ }^{6}$ and differ slightly from the $\mathrm{ICH}$ guideline, as the purpose and scope is to provide general instructions for planning the consent process and the appropriate involvement of children.

\section{New European regulations affect the IC process}

For the first time, the EU Clinical Trial Regulation makes the involvement of children in the consent process mandatory, according to age and maturity. ${ }^{7}$ Under the EU General Data Protection Regulation (GDPR), ${ }^{9}$ individuals normally gain the right to be asked for consent (or to withhold consent) for the collection and processing of their personal data between the ages of 13 and 16 years. In a clinical trial setting, where the age of consent to participate is generally older (14-18 years), this may create discrepancy. Recital 161 of the GDPR stipulates that the age of consent to personal data processing will be the same as the age to consent for clinical trial participation. ${ }^{9}$
However, it is important to distinguish between the requirement for consent for clinical trial participation and the requirements for lawful processing of personal data under the GDPR. The standards of quality (reliability of data) and patient safety for medicinal products fall under different legal bases. Therefore, the requirement for IC by the EU Clinical Trial Regulation is a safeguard, not a legal basis for data processing, and must not be confused with consent as a legal ground for processing personal data set out in Article 6(1)(a) of the GDPR. ${ }^{33}$

\section{The young people provide important expertise to paediatric trials}

For this guide, the young person's groups provided important input. This represents the direct voice of young people and is extremely valuable in the consent discussion. The importance of the opinions and experiences of children and their families is now becoming a crucial part in the development of new medicinal products, as recognised by many stakeholders. ${ }^{34-36}$

\section{Current existing guidance is not enough to design consents and assents for children}

To date, there are only a limited number of public ethical and practical guidance documents regarding consent and assent design specifically for paediatric clinical trials. Some learnt societies have provided articles, books, videos, and recommendations, practical guidance and training programmes for all stakeholders. ${ }^{20-25}$ However, none of these existing materials provide similarly detailed instructions for the design of the paediatric consent, assent or agreement document structure, and guide for the whole consent process, including the voice of children.

\section{Practical limitations and implementation of this guide}

Each Member States of the EU and European Economic Area has its own national legislation and detailed requirements for consent documents, ${ }^{4}$ and these vary among countries. Therefore, this guide should be used together with the local or national requirements. It is also important to acknowledge that while this guide contains instructional text (ie, 'should be'), these are not official requirements or legal guidance, but suggestions serving as an example for every age group. All the subject elements need to be adapted case-by-case according to the nature of the clinical trial protocol.

This guide is designed to support the consent process for paediatric clinical trials in Europe across all age groups. It can be used when preparing submission packages to competent 
Table 4 Trial specific information for informed consent and assent (agreements)

\begin{tabular}{|c|c|c|c|c|c|c|c|c|}
\hline \multirow{2}{*}{$\begin{array}{l}\text { Element } \\
\text { number }\end{array}$} & \multicolumn{4}{|c|}{ Age group in years } & \multirow[b]{2}{*}{ Legal representative(s) } & \multirow{2}{*}{$\begin{array}{l}\text { Elements to consider/information which } \\
\text { must be included into the assent/consent } \\
\text { document }\end{array}$} & \multirow[b]{2}{*}{ Questions to be addressed } & \multirow{2}{*}{$\begin{array}{l}\text { Notes and example methods/texts to } \\
\text { be used }\end{array}$} \\
\hline & $0-2$ & $2-5$ & $6-9$ & $10-18$ & & & & \\
\hline 1 & & & & & & $\begin{array}{l}\text { Title/topic of the trial/introduction/purpose } \\
\text { of the trial/size of the trial (how many } \\
\text { patients/participants, how many sites) }\end{array}$ & $\begin{array}{l}\text { What is the purpose of this trial? } \\
\text { Why is this trial needed? } \\
\text { Is there information about this trial } \\
\text { available somewhere? }\end{array}$ & $\begin{array}{l}\text { NOTE: EUCTR number and trial protocol code } \\
\text { must be added. The trial must be registered } \\
\text { in the official Trial Registry (EudraCT) before } \\
\text { the start of the trial. Additionally, in other } \\
\text { registries or websites according to national } \\
\text { requirements. }\end{array}$ \\
\hline 2 & & & & & & Introduction of the protocol (trial plan) & $\begin{array}{l}\text { What data is needed and why? } \\
\text { What will be done? }\end{array}$ & $\begin{array}{l}\text { NOTE: Use glossary of definitions or } \\
\text { dictionary of terms if the protocol is very } \\
\text { complex to explain. }\end{array}$ \\
\hline 3 & & & & & & $\begin{array}{l}\text { Participation/recruitment/child/adolescent } \\
\text { selection }\end{array}$ & $\begin{array}{l}\text { Why has the child/adolescent been } \\
\text { invited to participate in this trial? }\end{array}$ & \\
\hline 4 & & & & & & $\begin{array}{l}\text { Information about the institution/ } \\
\text { organisation (eg, hospital) and doctor(s)/ } \\
\text { investigator(s)/nurse(s)/trial personnel } \\
\text { conducting the trial }\end{array}$ & $\begin{array}{l}\text { Who are they? (eg, family GP) } \\
\text { Do they have required professional } \\
\text { expertise? } \\
\text { Will the doctor be the same } \\
\text { throughout the trial? }\end{array}$ & $\begin{array}{l}\text { NOTE: Include relevant information about } \\
\text { all relevant partners and personnel involved } \\
\text { in the conduct of the trial, including their } \\
\text { expertise. }\end{array}$ \\
\hline 5 & & & & & & $\begin{array}{l}\text { Introduction of the investigational } \\
\text { product(s)/placebo/device used in the trial }\end{array}$ & $\begin{array}{l}\text { What medicine(s)/device is it? } \\
\text { What (pharmaceutical) form is it? } \\
\text { How does it work and are there } \\
\text { side effects? What are the effects } \\
\text { on contraception/use of alcohol/ } \\
\text { smoking? } \\
\text { How will it be administered/taken? } \\
\text { Has it been tested in children } \\
\text { before? }\end{array}$ & $\begin{array}{l}\text { NOTE: The trial is intended to investigate } \\
\text { treatments for a medical condition which } \\
\text { occurs only in minors (children) or the trial is } \\
\text { essential with respect to minors- - same age } \\
\text { group as the child/adolescent. There must } \\
\text { be scientific grounds; a direct health } \\
\text { benefit for the child/adolescent or some } \\
\text { benefit for the population the child/ } \\
\text { adolescent represents, and there should } \\
\text { be only minimal risk and burden for } \\
\text { child/adolescents when compared with } \\
\text { standard care in that particular medical } \\
\text { condition. Explain the scientific reason/ } \\
\text { rationale for using placebo-if used } \\
\text { in the trial. }\end{array}$ \\
\hline 6 & & & & & & $\begin{array}{l}\text { Other treatments/alternatives/options for } \\
\text { clinical trials or diagnosis }\end{array}$ & $\begin{array}{l}\text { What are the current/existing } \\
\text { alternative methods/treatments if } \\
\text { the child/adolescent does not want } \\
\text { to take part in this trial? }\end{array}$ & $\begin{array}{l}\text { NOTE: The risks of premature termination } \\
\text { need to be explained to legal reps. (and } \\
\text { children if they have capacity to understand). } \\
\text { Reassurance should always be given that } \\
\text { withdrawal will not affect normal treatment } \\
\text { (alternative, standard) which should be } \\
\text { available. }\end{array}$ \\
\hline 7 & & & & & & Possible benefits/expected benefits & $\begin{array}{l}\text { Why might it be beneficial for the } \\
\text { child/adolescent to be in this trial? }\end{array}$ & $\begin{array}{l}\text { NOTE: Explain the possible benefits (direct or } \\
\text { some benefit for the population). }\end{array}$ \\
\hline 8 & & & & & & $\begin{array}{l}\text { Procedures/tests/measurements according to } \\
\text { the trial protocol } \\
\text { Pain (physical and emotional)/discomfort/ } \\
\text { fear must be prevented and minimised. Blood } \\
\text { volumes and sample methods should follow } \\
\text { guideline recommendations (EU Ethics Guideline, } \\
\text { R1, 2017). }\end{array}$ & $\begin{array}{l}\text { What will happen? } \\
\text { What tests will be done and when? } \\
\text { Why are these needed? } \\
\text { How do these affect normal daily } \\
\text { life, food/drink/sports and hobbies? } \\
\text { How does it differ from current/ } \\
\text { standard care? } \\
\text { Does it mean taking any time off } \\
\text { school? }\end{array}$ & $\begin{array}{l}\text { NOTE: Non-invasive procedures should } \\
\text { be preferred, where possible. Legal reps. } \\
\text { and children should be informed whether } \\
\text { the procedure is part of usual standard of } \\
\text { care or if it is part of the trial (extra), and } \\
\text { whether there is direct benefit or not. An } \\
\text { explanation about the procedure in honest } \\
\text { (not frightening) language must be offered } \\
\text { to both the legal representative and the child } \\
\text { prior to the procedure. }\end{array}$ \\
\hline 9 & & & & & & $\begin{array}{l}\text { Time/timing/trial duration (whole trial, at } \\
\text { specific site) } \\
\text { Visits/trial schedule }\end{array}$ & $\begin{array}{l}\text { How long will the trial take? } \\
\text { When are the trial visits? } \\
\text { How will it affect school/vacations/ } \\
\text { holidays/travel? }\end{array}$ & $\begin{array}{l}\text { NOTE: Use flowcharts } \\
\text { The expected duration of participation } \\
\text { must be stated. }\end{array}$ \\
\hline 10 & & & & & & $\begin{array}{l}\text { Risks/disadvantages/side effects of the } \\
\text { trial procedures/ investigational medicinal } \\
\text { product(s)/trial conduct/diagnosis }\end{array}$ & $\begin{array}{l}\text { What might inconvenience the child/ } \\
\text { adolescent? } \\
\text { Will there be extra pain/burden } \\
\text { or side effects—related to either } \\
\text { procedures/tests or to the trial } \\
\text { medication? }\end{array}$ & $\begin{array}{l}\text { NOTE: Risk/burden assessments must be } \\
\text { done prior to the trial (via scientificl } \\
\text { medical and ethical assessment conducted } \\
\text { by competent authorities). Possible realistic/ } \\
\text { anticipated risks/burden during the trial must } \\
\text { be described at a reasonable level during the } \\
\text { assent/consent process. }\end{array}$ \\
\hline 11 & & & & & & $\begin{array}{l}\text { Genetic testing } \\
\text { Genetic testing may represent benefit, risk or } \\
\text { burden. } \\
\text { Follow the national requirements/legislation. }\end{array}$ & $\begin{array}{l}\text { What kind of test? Blood/saliva/ } \\
\text { other type? Why is it taken? } \\
\text { How will it be taken? } \\
\text { What information will be collected } \\
\text { from the genetic test? } \\
\text { How will the information be used? } \\
\text { Who will be informed of the test } \\
\text { results? } \\
\text { What is the duration of sample } \\
\text { storage? }\end{array}$ & $\begin{array}{l}\text { A separate consent/assent may be } \\
\text { required for genetic tests. Disclosure } \\
\text { of genetic information to the child/ } \\
\text { adolescent requires precautions or } \\
\text { expert counselling (must be known } \\
\text { what information is collected, how the } \\
\text { information will be used, and how it is } \\
\text { interpreted.) Explain the scientific reason/ } \\
\text { rationale and the procedure for giving the } \\
\text { results in practice, if planned to do so in a } \\
\text { trial. NOTE: Only if relevant (trial includes } \\
\text { genetic testing). }\end{array}$ \\
\hline 12 & & & & & & $\begin{array}{l}\text { Use of ionising radiation } \\
\text { According to national regulations (eg, legal acts } \\
\text { for radiation). }\end{array}$ & $\begin{array}{l}\text { Is it used? How? } \\
\text { Are there any side effects? }\end{array}$ & $\begin{array}{l}\text { NOTE: Only if relevant (trial includes ionising } \\
\text { radiation) }\end{array}$ \\
\hline 13 & & & & & & $\begin{array}{l}\text { Biological samples/handling/ storing/banking } \\
\text { Biobank samples, retention and consent for future } \\
\text { processing of personal data should be discussed } \\
\text { in the protocol. } \\
\text { Follow the national requirements/legislation. }\end{array}$ & $\begin{array}{l}\text { What kind of samples? Tissue/blood/ } \\
\text { saliva/spinal fluid/other? } \\
\text { Why are they taken? } \\
\text { How will they be taken? } \\
\text { Where are the samples stored and } \\
\text { for how long? } \\
\text { Is it possible to cancel/withdraw } \\
\text { consent for future use? }\end{array}$ & $\begin{array}{l}\text { A separate consent/assent may be } \\
\text { required for biological samples. } \\
\text { Must comply with General Data Protection } \\
\text { Regulation (679/2016) and national } \\
\text { legislation. The collection and use of } \\
\text { samples must be described in consent/ } \\
\text { assent forms. } \\
\text { NOTE: Only if relevant (trial includes } \\
\text { biological samples). }\end{array}$ \\
\hline
\end{tabular}


Table 4 Continued

\begin{tabular}{|c|c|c|c|c|c|}
\hline \multirow{2}{*}{$\begin{array}{l}\text { Element } \\
\text { number }\end{array}$} & \multicolumn{4}{|c|}{ Age group in years } & \multirow[b]{2}{*}{ Legal representative(s) } \\
\hline & $0-2$ & $2-5$ & $6-9$ & 10-18 & \\
\hline
\end{tabular}

lements to consider/information which must be included into the assent/consent document

Possible future effects (infertility, birth efects, miscarriage)
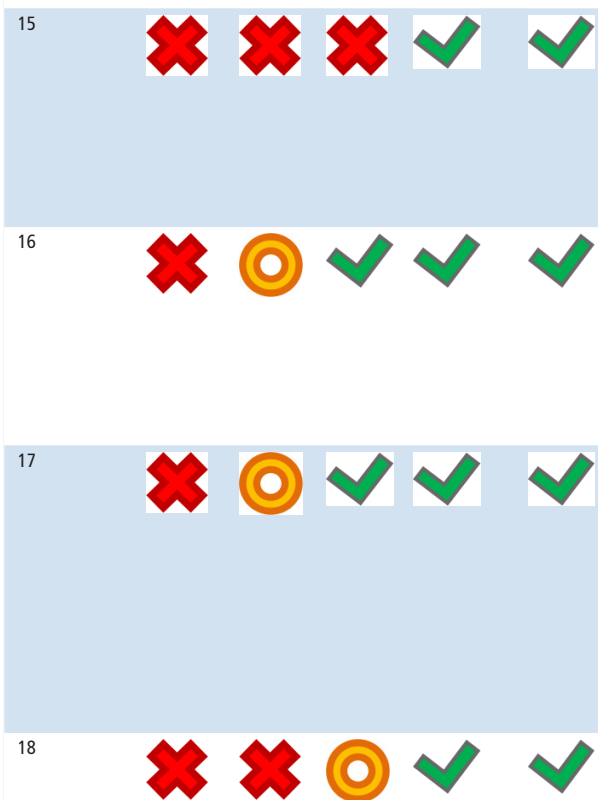

Special situations: Emergency/emancipated minor/pregnancy/breast feeding/unexpected problems

If during the trial the child reaches the age of point before the child/adolescent can continue participating in the trial.

Confidentiality/personal data protection Regulation (679/2016) for data protection. legal competence for giving consent (as defined national laws) consent must be obtained at that Must comply with EU General Data Protectio
Discontinuation by child/adolescent/right to withdraw/discontinuation for medical reasons (safety) by the sponsor. The procedures in place in the event of adverse reactions, including the documentation and time sensitive reporting throughout the duration of the trial must be explained during the consent assent process.
Questions to be addressed

- Can the trial medication or treatments have some effect on the fetus via mother or father, in case of the child/adolescent's pregnas
child/adolescent's girlfriend's child/adolescent
pregnancy?

What happens if this situation occurs?

Who will be told about this?

How will these types of situations be handled if they occur?

Who will be contacted?

Is there a need for prior consent?

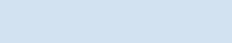

- What data from patient files and what additional information is needed and why?

- How will the data be used?

Who has access to this data? Must be clearly stated (using names, if required) who has access to anonymisation is done.

- How it may happen/when/for what reasons?

What happens later?

What are the options for further care/medication?

Compensation/expenses/NO incentives inducements used

Child/adolescents should not have to pay for IMPs/auxiliary products used fo administration and procedures by the administration and procedures by the protocol-unless the national law provides
otherwise. All compensations should be accordin to national requirements.

What expenses are expected during this trial? (exact level)

What costs will be covered by the trial/sponsor/hospital?

Notes and example methods/texts to be used

NOTE: Information about the potential eratogenic risks during pregnancy/ fertility (both females and males) should be discussed, and also the possibility to use contraception, and what type of contraception should be used if it is required. Explain what should happen if pregnancy arises during the trial.

NOTE: The protocol should define emergency situations and conditions (eg, time lag until consent is signed) for deferred consent (can be delayed and sought as soon as possible after inclusion). Consent may be deferred in certain emergency situations. Emergency: Shortened time for decision-full explanation should follow later.

NOTE: Regulatory Authorities have legal permission to have access to research documents and data during inspections and audits. The data will be stored anonymously, and the researcher will have access to it. Explain what anonymisation means.

NOTE: Identification of possible risks, minimising and monitoring the risksassent/consent should include an explanation about the probability and magnitude of harm anticipated in the trial and how this will be minimised. followed and handled. Stopping rules must included in the NOTE: Cla authorities regarding the right (or not) to authorities regarding the right (or not) to and samples already collected destroyed.

NOTE: No financial contribution/

inducements should be offered, except

compensation for the parents/ legal

representatives' expenses and loss of

earnings directly related to the child's

participation. A small token of appreciation may be acceptable-but needs to be approved by the Ethics Committee (EC) through review/assessment. Children do not need detailed reimbursement information if not directly related to personal compensations (eg travels, meals, etc). Legal reps. need al information of the compensations and reimbursements.

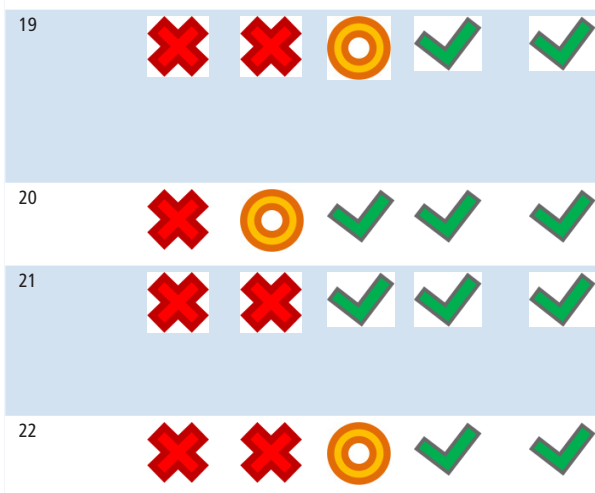

Insurance

Information about applicable damage compensation must be included. Compensation should be assured for damages. Member States should ensure that a system for compensation for damages is in place and appropriate-also sponsor's responsibility. After trial/follow-up measurements

Results of the trial

formation about the Competent Authority (CA) authorisations and Ethics Committe (EC) review/approvals including the appropriate expertise used in the assessment. The reviewers should be independent of the sponsor, the investigator and the trial.

Information about the sponsor/funding of the trial

Contact information
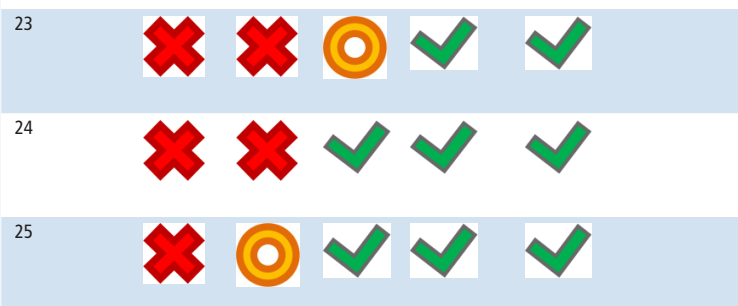

25
Confirmation of understanding In the consent/assent discussion it must be verified that everyone (legal reps./child) have understood the information.
- What possible damages could be expected during the trial (ie, what may go wrong) and how are these covered by insurance? (Exactly)

NOTE: Damage compensation is mandatory as per CTR and should be ensured by Member States. Insurance should not waive liabilities regarding longterm effects (delayed effects are typical in children when they grow up).

- Will the trial medication be available after the trial?

What happens after the trial?

- When is it expected to have trial results?

- Will child/adolescent/legal reps. be informed of the results?

\section{Who has reviewed/approved} the trial?

Has the review been undertaken by people who have official authority, and expertise for the assessment? this legal and safe?)

Who will fund this trial?

Do they pay the trial personnel directly?

- Who can be contacted at any time/ for any reason during the trial? How should they be contacted?

- Were answers provided to all the questions asked by the child/ adolescent and/or legal reps.?

adolescent and/or legal reps.? and need to be resolved? trial results must be stated. The information should include a summary of results presented in terms understandable to a layperson and must be available through EU database (portal).

NOTE: Should be explained who has reviewed/approved the protocol, but they have not decided on behalf of potential child/adolescents!

NO need to include information about EC approval in the young child's assent, as they do not understand the concept of 'ethics'. NOTE: Should be stated that the hospital receives money; not the investigator directly. Need to be clear interest differentiation between the investigator and sponsor. NOTE: Always give contact information to all participants.

NO need to have contact information in assent/consent for very young children. NOTE: You may use an additional summary leaflet, but it depends on the complexity of the trial.
NOTE: Information about availability of

*European Medicines Agency, 2021. Reproduced with permission. 
The guide data was collected by literature search. The legal, ethical and regulatory requirements for paediatric clinical trials and consent process were analysed, structured and divided to table format of 30 separate elements (rows). All elements were further divided into 5 sections; I-V (columns). All relevant references were included.

All 30 elements were sub-divided and analysed per 4 age groups according the EU Ethics Guideline (R1). The 30 elements were further dived to two tables: 1) General information for Informed Consent and Assent (Agreements), and 2) Trial Specific Information for Informed Consent and Assent (Agreements). For table 2, one additional sixth section (column VI) was added for the element numbering. A 3-level "traffic light" recommendation per each age group was designed.

Three national groups of European Young Person's Advisory Groups Network (eYPAGnet) reviewed the data of tables 1) and 2) and provided feedback for all 30 elements by monographic sessions leaded by the group facilitators. The report of collated data of three groups was integrated to the table section IV: "Questions to be addressed".

The relevant introduction with methods and list of abbreviations and definitions was added to the guide tables. The complete guide was reviewed by the Office of the Paediatric Medicines (EMA).

The guide document with all references was finalized according EMA's comments and published on Enpr-EMA website.

Figure 1 The flowchart of the development process of the informed consent and assent guide.

authorities and ethics committees. This guide provides practical ideas and examples about how to present relevant information to children in the consent process, and it serves also as an example to encourage to seek comments from the local patient and parent groups when designing consent and assent documents. The content is also applicable to electronic consent. The document will be updated by the Enpr-EMA secretariat and it will be open for public comments for further improvement.

\section{CONCLUSION}

This work is the first to extensively collate and document all the current legal, regulatory and ethical guidelines on the consent and assent process for paediatric clinical trials in Europe, together with input from adolescents. It is a single easy-to-use publicly available guide for all stakeholders and the contents can be adapted to trials in case-by-case.

Although the new EU Clinical Trial Regulation will harmonise Clinical Trial Application practices in Europe, it does not contain specific guidance for the paediatric clinical trial consent process. As there are still many national legal differences in the requirements for consent and assent documents, this guide may increase

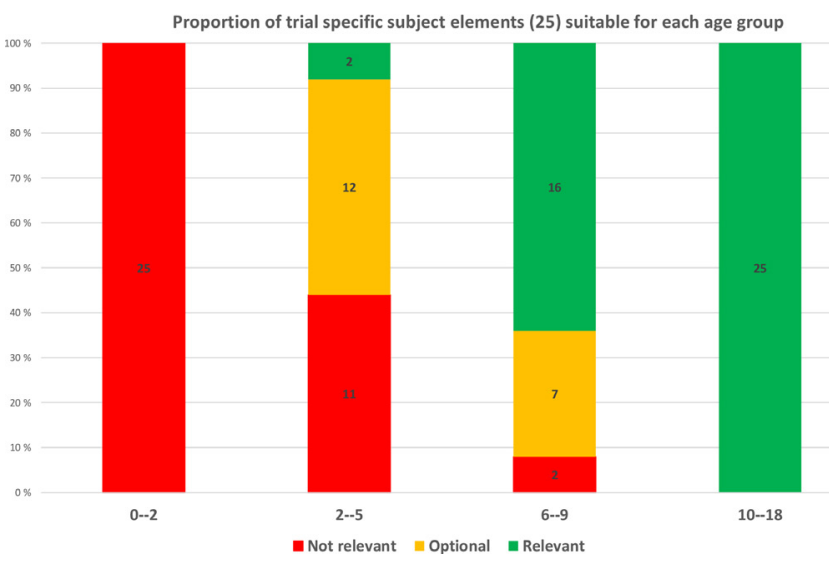

Figure 2 Proportion of information of 25 trial-specific subject elements relevant to each four age groups (red=not relevant, orange $=$ optional, green=relevant). the level of ethical standards and facilitate the harmonisation of paediatric consent and assent documents in Europe.

Acknowledgements Special thanks go out to eYPAGnet group leaders; Jennifer Preston, GenerationR (England), Pamela Dicks, ScotCRN (Scotland), Begonya Nafria Escalera, Kids Barcelona (Spain) and Segolene Gaillard, Kids France (France) and their great effort when collecting comments from all national adolescent groups giving valuable add to this guideline.

Contributors Literature search and guide document table design was done by PL, MK, VG, HG, MD-K, HD, DN, GBB, JC, JD and DH. Data figures and tables to the article were done by PL. Data interpretation, writing and approval of final version were done by all authors. Guarantor: Pirkko Lepola (PL)

Funding The authors have not declared a specific grant for this research from any funding agency in the public, commercial or not-for-profit sectors.

Competing interests $\mathrm{PL}$ is the Chair of the Coordinating Group of the European Network of Paediatric Research at the European Medicines Agency (Enpr-EMA), and all authors have been members of the ad hoc Enpr-EMA Ethics Working Group during this work.

Patient consent for publication Not applicable.

Provenance and peer review Not commissioned; externally peer reviewed.

Data availability statement Data are available in a public, open access repository. All data are publicly available via Enpr-EMA website: https://www.ema. europa.eu/en/documents/other/assent/informed-consent-guidance-paediatricclinical-trials-medicinal-products-europe_en.pdf.

Open access This is an open access article distributed in accordance with the Creative Commons Attribution Non Commercial (CC BY-NC 4.0) license, which permits others to distribute, remix, adapt, build upon this work non-commercially, and license their derivative works on different terms, provided the original work is properly cited, appropriate credit is given, any changes made indicated, and the use is non-commercial. See: http://creativecommons.org/licenses/by-nc/4.0/.

\section{ORCID iD}

Pirkko Lepola http://orcid.org/0000-0001-9663-0872

\section{REFERENCES}

1 Eurostat. European population, proportion of the population by age, 2021. Available: https://ec.europa.eu/eurostat/databrowser/view/tps00001/default/table?lang=en [Accessed 01 Jul 2021].

2 The European Union clinical trials register. Available: https://www.clinicaltrialsregister. eu/ctr-search/search [Accessed 01 Jul 2021].

3 European Union. Regulation (EC) NO 1901/2006 of the European Parliament and of the Council of 12 December 2006 on medicinal products for paediatric use and amending regulation (EEC) NO 1768/92, directive 2001/20/EC, directive 2001/83/EC and regulation (EC) NO 726/2004, 2007. Available: https://eur-lex.europa.eu/legalcontent/EN/TXT/?uri=CELEX:32006R1901 [Accessed 01 Jul 2021]. 
4 Lepola P, Needham A, Mendum J. Informed consent and Assent tool kit for paediatric clinical trials in Europe. Arch Dis Child2016.

5 Giannuzzi V, Altavilla A, Ruggieri L, et al. Clinical trial application in Europe: what will change with the new regulation? Sci Eng Ethics 2016;22:451-66.

6 European Union Commission ad hoc group. Recommendations of the AD hoc group for the development of implementing guidelines for directive 2001/20/EC relating to good clinical practice in the conduct of clinical trials on medicinal products for human use. ethical considerations for clinical trials on medicinal products conducted with the paediatric population. revision 1. 18 September 2017. Eudralex 10, chapter IVAdditional information. Available: https://ec.europa.eu/health/sites/health/files/files/ eudralex/vol-10/2017_09_18_ethical_consid_ct_with_minors.pdf [Accessed 01 Jul 2021].

7 European Union. Regulation EU no 536/2014 of the European Parliament and of the Council of 16 April 2014 on clinical trials on medicinal products for human use, and repealing directive 2001/20/EC. 16 June 2014 (will become applicable no earlier than 28 may 2016), 2016. Available: https://eur-lex.europa.eu/legal-content/EN/TXT/?uri= CELEX:32014R0536 [Accessed 01 Jul 2021].

8 European Union. Directive 2001/20/EC of the European Parliament and of the Council of 4 April 2001 on the approximation of the laws, regulations and administrative provisions of the member status relating to the implementation of good clinical practice in the conduct of clinical trials on medicinal products for human use. official Journal of the European communities 2011. L 121/34-44. Available: https://eur-lex. europa.eu/legal-content/EN/TXT/?uri=CELEX:02001L0020-20090807 [Accessed 01 Jul 2021].

9 European Union. Regulation (EU) 2016/679 of the European Parliament and of the Council of 27 April 2016 on the protection of natural persons with regard to the processing of personal data and on the free movement of such data, and repealing directive 95/46/EC (General data protection regulation, GDPR). Available: https://eurlex.europa.eu/legal-content/EN/TXT/?uri=CELEX\%3A02016R0679-20160504\&qid= 1532348683434 [Accessed 01 Jul 2021].

10 World Medical Association. WMA Declaration of Helsinki - Ethical Principles for Medical Research Involving Human Subjects. 64th WMA General Assembly, Fortaleza, Brazil, 2013. Available: https://www.wma.net/what-we-do/medical-ethics/declarationof-helsinki/ [Accessed 01 Jul 2021].

11 International Conference of Harmonization. ICH guideline for good clinical practice E6 (R2). 15Dec2016. Available: https://www.ema.europa.eu/en/ich-e6-r2-good-clinicalpractice [Accessed 01 Jul 2021].

12 United Nations Human Rights. Convention on the rights of the child. adopted and opened for signature, ratification and accession by general assembly resolution 44/25 of 20 November 1989, entry into force 2 September 1990, in accordance with article 49, 1990. Available: http://www.ohchr.org/en/professionalinterest/pages/crc.aspx [Accessed 01 Jul 2021].

13 European Union Agency for Fundamental Rights. Eu charter of fundamental rights, article 24: rights of the child. Available: https://fra.europa.eu/en/charterpedia/article/ 24-rights-child [Accessed 01 Jul 2021].

14 The European Young Person's Advocacy Group - eYPAgnet. Available: https://www. eypagnet.eu/ [Accessed 01 Jul 2021].

15 European Medicine Agency. Principles on the involvement of young patients/ consumers within EMA activities, 24 may 2017, EMA/494077/2016. Available: https:// www.ema.europa.eu/en/documents/regulatory-procedural-guideline/principlesinvolvement-young-patients/consumers-within-ema-activities_en.pdf [Accessed 01 Jul 2021].

16 The European network of paediatric research at the European medicines Agency (Enpr-EMA). Available: https://www.ema.europa.eu/en/partners-networks/networks/ european-network-paediatric-research-european-medicines-agency-enpr-ema [Accessed 01 Jul 2021].
17 Turner MA, Attar S, de Wildt SN, et al. Roles of clinical research networks in pediatric drug development. Clin Ther 2017;39:1939-48.

18 Ruperto N, Eichler I, Herold R, et al. A European network of paediatric research at the European medicines Agency (Enpr-EMA). Arch Dis Child 2012;97:185-8.

19 Enpr-EMA Ethics Working Group. Informed consent for paediatric clinical trials in Europe, 2015. Available: http://tinyurl.com/h2xrlvr [Accessed 01 Jul 2021].

20 ERIC Compendium. Ethical research involving children; ethical guidance: informed consent, 2013. Available: http://childethics.com/wp-content/uploads/2013/10/ERICcompendium-Ethical-Guidance-Informed-consent-section-only.pdf [Accessed 01 Jul 2021].

21 The RESPECT project investigated children's participation in clinical trials. Available: https://issuu.com/respect_patient_needs/docs/respect_book?viewMode=doublePage [Accessed 01 Jul 2021].

22 Nuffield Council on bioethics. children and clinical research: ethical issues. ISBN: 978-1-904384-31-1, 2015. Available: https://www.nuffieldbioethics.org/topics/ research-ethics/children-and-clinical-research [Accessed 01 Jul 2021].

23 The $\mathrm{c4c}$ (conect4children) - a collaborative network for European clinical trials for children. Large European infrastructure project. Available: https://conect4children.org/ [Accessed 01 Jul 2021].

24 The paediatric clinical research infrastructure network (PedCRIN) project. Available: https://www.ecrin.org/projects/pedcrin [Accessed 01 Jul 2021].

25 Jackson SM, Daverio M, Lorenzo Perez S. The i-CONSENT improving informed consent for novel vaccine research in a pediatric hospital setting using a blended ResearchDesign approach front.. Pediatr.

26 Enpr-EMA Ethics Working Group. Recommendations regarding the contents of the various subject elements of consent / assent forms for each paediatric age group, to be considered when designing these documents. Available: https://www.ema.europa. eu/en/documents/other/assent/informed-consent-guidance-paediatric-clinical-trialsmedicinal-products-europe_en.pdf [Accessed 01 Jul 2021].

27 Beauchamp T, Childress J. Principles of biomedical ethics. 6 edn. New York: Oxford University Press, 2009.

28 Abdel-Rahman SM, Reed MD, Wells TG, et al. Considerations in the rational design and conduct of phase I//I pediatric clinical trials: avoiding the problems and pitfalls. Clin Pharmacol Ther 2007;81:483-94.

29 Kauffman RE. Clinical trials in children: problems and pitfalls. Paediatr Drugs 2000;2:411-8.

30 Turner MA, Hirschfeld S. Frameworks for evaluating medicines in children. Clin Ther 2017;39:1949-58.

31 Lagler FB, Hirschfeld S, Kindblom JM. Challenges in clinical trials for children and young people. Arch Dis Child 2021;106:321-5.

32 International Conference of Harmonization. ICH E11(R1) step 5 guideline on clinical investigation of medicinal products in the pediatric population and the related Addendum. Available: https://www.ema.europa.eu/en/ich-e11r1-step-5-guidelineclinical-investigation-medicinal-products-pediatric-population [Accessed 01 Jul 2021].

33 European Commission, Directorate-General for Health and Food Safety. Health systems and products, medical products - quality, safety and innovation. question and answers on the interplay between the clinical trials regulation and the general data protection regulation. (NO date). Available: https://ec.europa.eu/health/sites/health/ files/files/documents/qa_clinicaltrials_gdpr_en.pdf [Accessed 01 Jul 2021].

34 Bate J, Ranasinghe N, Ling R, et al. Public and patient involvement in paediatric research. Arch Dis Child Educ Pract Ed 2016;101:158-61.

35 Tume LN, Preston J, Blackwood B. Parents' and young people's involvement in designing a trial of ventilator weaning. Nurs Crit Care 2016;21:e10-18.

36 Tsang VWL, West L, Woods C, et al. Role of patients and parents in pediatric drug development. Ther Innov Regul Sci 2019;53:601-8. 